\title{
Does the Medical Insurance System Play a Real Role in Reducing Catastrophic Economic Burden in Elderly Patients with Cardiovascular Disease in China? Implication for Accurately Targeting Vulnerable Characteristics.
}

\author{
Meiyan Ma \\ Harbin Medical University School of Public Health \\ Ye Li ( $D$ liye8459@163.com ) \\ Harbin Medical University https://orcid.org/0000-0001-8492-1808 \\ Nianshi Wang \\ Harbin Medical University School of Public Health \\ Qunhong Wu \\ Harbin Medical University School of Public Health \\ Mingli Jiao \\ Harbin Medical University School of Public Health \\ Linghan Shan \\ Harbin Medical University School of Public Health \\ Tao Sun \\ Hangzhou Normal University Hangzhou School of Medicine \\ Heng Li \\ Shanghai Jiao Tong University School of Public Health \\ Han Gao \\ Tumor Hospital of Harbin Medical University \\ Xuelian Fu \\ Second Affiliated Hospital of Harbin Medical University \\ Wanxin Tian \\ Harbin Medical University School of Public Health \\ Qi Xia \\ Harbin Medical University School of Public Health \\ Yanhua Hao \\ Harbin Medical University School of Public Health

\section{Baoguo Shi} \\ Minzu University of China
}


Keywords: cardiovascular disease, catastrophic health expenditure, impoverishment by medical expense, medical insurance, elderly households, China

Posted Date: May 12th, 2020

DOI: https://doi.org/10.21203/rs.3.rs-25122/v1

License: (c) (7) This work is licensed under a Creative Commons Attribution 4.0 International License. Read Full License 


\section{Abstract}

Background: The vulnerability of cardiovascular disease (CVD) patients' health abilities, combined with the severity of the disease and the overlapping risk factors, can cause such people to bear the economic burden of the disease due to the use of medical services. We estimated the economic burden of patients with CVD,and identified the weak link in the design of the medical insurance.

Methods: Data from 5,610 middle-aged and elderly with CVD were drawn from the 2015 wave of China Health and Retirement Longitudinal Study (CHARLS). The recommended method of the World Health Organization (WHO) was adopted to calculate catastrophic health expenditure (CHE), impoverishment by medical expenses (IME), and applied the treatment-effect model to analyze the determinants of $\mathrm{CHE}$.

Results: The incidence of CHE was $19.9 \%$ of the CVD, compared to $7.6 \%$ of the sample households trapped in IME. The incidence of CHE in CVD participating in medical insurance was $2.6 \%$ higher than for uninsured families (16.3\%).Family size, health satisfaction,combine with other chronic diseases, having hospitalization and disabled members, and participating in insurance were found to be significantly associated with the likelihood of $\mathrm{CHE}$.

Conclusions: Elderly with physical vulnerabilities were more prone to CHE. The medical insurance only reduced barriers to accessing health resources for elderly with CVD, but lacked policy inclination for high-utilization populations, and had poorly accurate identification of vulnerable characteristics of CVD, which in turn affects the economic protection ability of the medical insurance. The dispersion between the multiple medical security systems leads to the existence of blind spots in the economic risk protection of individuals and families.

\section{Background}

Aging, rapid urbanization, and shifting disease patterns are causing cardiovascular disease (CVD) to become established as one of the primary diseases in the world. ${ }^{1.2}$ Worldwide, roughly 17.9 million people die of CVD each year, and the absolute number of deaths from chronic CVD worldwide increased by $42.4 \%$ between $1990-$ 2015 (2017). ${ }^{3,4}$ The incidence and mortality of CVD are also serious in China. As of 2015, there were 290 million people suffering from CVD in China, including more than 9.5 million cases of heart disease. ${ }^{5}$ In addition, between 1990-2013, the total number of CVD deaths increased by $46 \%$ in China, mainly due to population aging. ${ }^{6}$ The increasing trend of CVD has brought a heavy economic burden to the world at the population and household levels. ${ }^{7}$ It is estimated that as of 2015 , the estimated annual global cost of CVD is expected to increase by $16 \%$, from 906 billion to more than 104.4 million by $2030 .{ }^{8}$ In India, $25 \%$ of families with a member with CVD experience catastrophic expenditure, and $10 \%$ are driven into poverty. ${ }^{9}$

The particularity of the internal disease structure and the characteristics of the elderly have made China one of the countries with a high incidence of CVD. In China, the Disability Adjusted of Life Years(DALY) caused by cardiovascular disease has reached 582.255 million, accounting for roughly $20 \%$ of the world's cardiovascular disease, which is nearly $9 \%$ higher than the international average. ${ }^{10}$ Annual inpatient care cost has risen at a steady rate of $30 \%$ since $2004 .{ }^{11}$ Compared to Western Europe, China suffers a $50 \%$ higher mortality rate from CVD and faces a larger economic burden. ${ }^{12}$ Annual direct medical expenses for cardiovascular diseases in 
China are more than 130 billion yuan, accounting for more than $22 \%$ of the total medical expenses in China during the same period, which is $10 \%$ higher than Australia. ${ }^{13}$ Some research indicates that during the 30 years from 2010-2040, the annual economic benefits of reducing cardiovascular mortality by $1 \%$ in China is equivalent to $68 \%$ of real GDP in 2010 , exceeding US $\$ 10.7$ trillion. ${ }^{14}$

China's basic medical insurance system consists of three types of medical insurance scheme: urban employees' insurance medical(MIUE), urban resident insurance medical(MIUR), and the new rural cooperative medical system(NCMS). ${ }^{15}$ The basic medical insurance for economic protection with two basic goals: first, to ensure that all people have access to high-quality care; and second, that everyone has the ability to pay for these services to maintain and improve their health. ${ }^{16}$

China has basically achieved $95 \%$ coverage of medical and health services. However, the inefficiency of the health care system and the uneven distribution of medical resources make the cost-effectiveness of continuous medical reforms lower, and the coverage and depth of the medical insurance system needs to be improved. Studies have demonstrated that the actual effect of this coverage has been offset by the rapid escalation of medical expenses,especially for the elderly group that combines age and disease. ${ }^{17}$ Some scholars measured the disease burden of CVD patients aged 60 years and older in 2011-2013 and found that the direct and indirect medical costs of residents rose from 4,938 yuan to 5,717 yuan, and the OOP (Out-of-pocket)increased by roughly 12 percentage points (from $58.1-70 \%$ ). ${ }^{18}$ The resident's medical insurance reimbursement ratio is much lower than the European Union's (EU) major disease reimbursement ratio of not less than $60 \% .{ }^{19}$ The World Health Organization (WHO) reports that a reasonable OOP is $15-20 \% .{ }^{20}$ Once the literature exceeds the prescribed warning value, it will often cause vulnerable groups, such as rural residents and the elderly with low economic incomes, to fall into excessive cash health expenditures, resulting in "impoverishment by medical expenses" and "returning from poverty."

The above data indicate that the vulnerability of CVD patients' health abilities, combined with the severity and recurrence of the disease itself and the overlapping risk factors, caused such people to bear the heavy economic burden of the disease due to the use of medical services. Therefore, in the study we adopt the WHO recommended method to verify the health-reducing effect of the health care system, that is, whether the medical insurance system reduces the risk of $\mathrm{CHE}$ in cardiovascular patients over the age of 45 . And it is important to understand whether medical insurance system increases the accessibility and affordability of health care, which provides good evidence for further ways to alleviate health poverty.

\section{Methods}

\section{Data source and sampling method}

The data used to calculate the rates of catastrophic health expenditure (CHE) and impoverishment by medical expenses (IME) were obtained from the 2015 China Health and Pension Tracking Survey (CHARLS) database, which is designed to collect microscopic information from > 45-year-olds. CHARLS covers 450 communities in 150 counties from 28 of the 32 provinces in mainland China. Face-to-face household interviews were conducted by qualified investigators. Households were randomly selected from maps and listings within each rural or urban community by four-stage stratified cluster sampling to select eligible individuals. Data were collected 
through questionnaires, and quality control was implemented by supervisors and included GPS comparison, data verification, recording verification, and telephone verification. A total of 5,610 samples (2,507 households) were finally obtained after cleaning the incomplete data and missing values.

\section{Statistical analysis}

\section{Calculation method for CHE and IME}

We adopted the WHO's recommended method to calculate CHE and IME. ${ }^{21}$ CHE was defined as an OOP payment for health care equaling or exceeding $40 \%$ of a household's capacity to pay. IME was defined as consumption expenditure equal to or higher than household subsistence expenditure but lower than the subsistence expenditure (SE) net of OOP health payments. The key expenditure indicators involved in the calculation process were as follows:

Equivalent family size:

eqsize $_{h}=$ hhsize $_{h}{ }^{0.56}$

Equivalent food expenditure: total household food expenditure divided by equivalent family size

$$
\text { eqfood }_{h}=\frac{\text { food }_{h}}{\text { eqsize }_{h}}
$$

Poverty Line (pl): the weighted average food expenditure of a household, whose food expenditure as a share of household consumption expenditure fell between the 45th and 55th percentiles of the entire sample.

$$
p l=\frac{\sum w_{h} * \text { eqfood } h}{\sum w_{h}}
$$

Household subsistence expenditure (SE): was calculated using food expenditure as a share of total household consumption expenditure.

$$
s e_{h}=p l * e \text { size }_{h}
$$

A household's capacity to pay (CTP): was defined as non-subsistence spending of a household as a share of total household consumption expenditure. 


$$
\begin{gathered}
c t p_{h}=\exp _{h}-s e_{h} \quad \text { if } \text { se }_{h} \leq \text { food }_{j} \\
c t p_{h}=\exp _{h}-\text { food }_{h} \text { if } \operatorname{se}_{h}>\text { food }_{h}
\end{gathered}
$$

Out-of-pocket health expenditure (OOP): the payments made by households for their health services without third-party compensation.

$$
\operatorname{oopctp}_{h}=\frac{o o p_{h}}{c t p_{h}}
$$

Household consumption expenditure (exp): comprises both monetary and in-kind payments on all goods and services and the money value of the consumption of home-made products.

The consumption quintile: ranked by equivalized per capital household consumption expenditure weighted with the standard household size rather than the actual household scale.

eq $\exp _{\mathrm{h}}=\exp _{\mathrm{h}} /$ eqsize $_{\mathrm{h}}$

\section{Treatment effect model}

The relationship between participating in the medical insurance system and $\mathrm{CHE}$ is characterized by a joint causal relationship. There are implicit selection biases in participating in the medical insurance system, such as the average community participation rate, self-assessment of health status, and other unobserved characteristics associated with initial selection. To address the bias caused by hidden selectivity bias and joint causality, we applied a instrumental variable (IV) method called the therapeutic effect model. ${ }^{22,23}$

\section{Instrument indicators}

We assume that indicators of medical insurance are endogenous. In order to address this endogeneity, we needed instrumental variables, which are related to endogenous predictors (medical insurance) but are not related to the error term of outcome variables(CHE) ${ }^{24}$ The premise of using the instrumental variable method is that there are endogenous variables in the regression equation. So,it is necessary to identify endogenous variables(whether participation in medical insurance) in the regression equation.In our paper, we verify this problem by DWH test. In other words, the DWH test checks examines whether the endogenous predictor is truly endogenous. . The heterogeneity test result shows that, $P=0.000<0.05$, so we use the DWH text)

By reviewing existing literature,we initially identified two possible instruments: self-assessment of health status and average community participation rate.Generally speaking self-reported poorly-healthy groups are more likely to choose to take insurance medical to maintain their health. ${ }^{25}$ In addition, the average community participation rate of residents' basic medical insurance will have an impact on the willingness of families to participate in insurance.People living in the same community have certain common characteristics, such as family economic level and health management awareness, which will make them participate in medical insurance.Moreover, the basic medical insurance plan in China is a community or company-based unit. For 
example, the MIUE is driven by the company, and the NCMS is that the village cadres mobilize the villagers to participate in the medical insurance scheme, so that the community participation rate is highly correlated with the willingness to participate in the family. ${ }^{26}$

Good instrument should satisfy two main criteria known as relevance and validity criteria, that is to say, good instruments would be correlated with the endogenous variable (relevance criteria) but not to be correlated with the error terms in the model of the outcome variable (validity criteria).

We use the Over-identification Test and GMM regression to check the validity and relevance. ${ }^{27,28}$ In addition, in order to further investigate the weak instrumental variable problem, we also perform redundancy-test. The results show that community participation rate becomes our ultimate effective instrumental variable. The results regarding the validity and relevance are presented in Table 1.

Table 1

Validity test and correlation test

\begin{tabular}{|c|c|c|c|c|}
\hline Instrumental variable & DWH test & $\begin{array}{l}\text { Over-identification } \\
\text { test }\end{array}$ & F test & Redundancy test \\
\hline $\begin{array}{l}\text { Community participation } \\
\text { rate }\end{array}$ & \multirow{2}{*}{$\begin{array}{l}\operatorname{chi} 2(1)=4.5588 \\
(p=0.0327< \\
0.05) *\end{array}$} & \multirow{2}{*}{$\begin{array}{l}\operatorname{chi} 2(1)=1.6578 \\
(p=0.1979>0.05)\end{array}$} & \multirow[t]{2}{*}{$\begin{array}{l}F=24.3034> \\
10\end{array}$} & $\begin{array}{l}\text { Chi-sq. }(1)= \\
0.0000^{*}\end{array}$ \\
\hline Self-assessed health & & & & $\begin{array}{l}\text { Chi-sq. }(1)= \\
0.3873\end{array}$ \\
\hline
\end{tabular}

The treatment effect model includes a two-stage regression. In the first phase, we regression the outcome variables of the covariates (the heterogeneity test results show that $P=0.000<0.05$, so we use GMM as our regression equation); based on the results of the first phase, we add instrument variables and the outcome variable performs a quadratic regression.

\section{Outcome variable}

We created a binary indicator for $\mathrm{CHE}$ as the outcome variable $(1=$ occurrence, $0=$ no occurrence $)$.

\section{Covariates}

In our study, we used three sets of information as covariates for this paper: Social demographic characteristics, specifically age, gender, marital status, education level of household head, family size, and having a member over 65 years old. The health status of family members, including whether the household has at least one member with a chronic disease, who has been admitted to the hospital, or has a disability. The demand and utilization of health services for household heads, mainly including hospitalization rate, outpatient rate, and non-admission rate (defined as the percentage of patients who need to be hospitalized but are not hospitalized).

\section{Results}

\section{Sample characteristics}

Table 2 summarizes the characteristics of CVD in 2015. The total sample comprised 2,507 households and 5,610 individuals, of which $50.2 \%$ of household heads with CVD were male, and around $65.7 \%$ of the elderly were aged $<64$. Over $59.4 \%$ had an elementary to junior high education level,only $23.3 \%$ of the CVD patients had 
a health satisfaction status of "good," with $>60.4 \%$ having one or more other chronic diseases.Furthermore, $97.1 \%$ of the CVD patients had medical insurance. 
Table 2

Patients' demographic characteristics

\begin{tabular}{|c|c|c|}
\hline Variables & Variable value & Percentage(\%) \\
\hline \multirow[t]{2}{*}{$\mathrm{CHE}$} & No & 80.1 \\
\hline & Yes & 19.9 \\
\hline \multirow[t]{2}{*}{ Participate in medical insurance scheme } & No & 2.9 \\
\hline & Yes & 97.1 \\
\hline \multirow[t]{2}{*}{ Gender of household head } & Female & 49.8 \\
\hline & Male & 50.2 \\
\hline \multirow[t]{2}{*}{ Marital status of household head } & Others & 15.0 \\
\hline & Married & 85.0 \\
\hline \multirow[t]{3}{*}{ Education level of household head } & Illiteracy & 21.5 \\
\hline & Elementary to junior high & 59.4 \\
\hline & High school and above & 15.4 \\
\hline \multirow[t]{3}{*}{ Family size } & 1 & 62.6 \\
\hline & $2-3$ & 31.9 \\
\hline & More than 3 people & 5.5 \\
\hline \multirow[t]{4}{*}{ Age of household head } & $45-54$ & 32.5 \\
\hline & $55-64$ & 33.2 \\
\hline & $65-74$ & 23.5 \\
\hline & More than 75 years old & 8.7 \\
\hline \multirow[t]{2}{*}{ Having members over 65 years old } & No & 44.2 \\
\hline & Yes & 54.0 \\
\hline \multirow[t]{4}{*}{ Combined with other chronic diseases } & No & 39.6 \\
\hline & 1 & 35.5 \\
\hline & 2 & 21.3 \\
\hline & 3 & 3.6 \\
\hline \multirow[t]{2}{*}{ Having hospitalized members } & No & 87.1 \\
\hline & Yes & 12.2 \\
\hline \multirow[t]{2}{*}{ Having disabled members } & No & 3.1 \\
\hline & Yes & 92.3 \\
\hline
\end{tabular}




\begin{tabular}{|c|c|c|}
\hline Variables & Variable value & Percentage(\%) \\
\hline \multirow[t]{5}{*}{ Health satisfaction } & Very good & 4.2 \\
\hline & Good & 19.1 \\
\hline & Fair & 48.8 \\
\hline & Poor & 20.5 \\
\hline & Very poor & 6.8 \\
\hline \multirow[t]{5}{*}{ Household consumption per capital quintile } & Lowest & 20.7 \\
\hline & 2 & 21.3 \\
\hline & 3 & 19.9 \\
\hline & 4 & 20.2 \\
\hline & Highest & 17.9 \\
\hline \multirow[t]{3}{*}{ Region } & Eastern & 33.7 \\
\hline & Middle & 46.3 \\
\hline & Western & 20.0 \\
\hline \multirow[t]{2}{*}{ location } & Rural & 75.1 \\
\hline & Urban & 24.9 \\
\hline
\end{tabular}

\section{Health-care needs and service utilization}

Table 3. Health care demand, service utilization, and reimbursement of household head 
Table 3

Health care demand, service utilization, and reimbursement of household head

\begin{tabular}{|c|c|c|c|c|c|c|}
\hline & & $\begin{array}{l}\text { Prevalence } \\
(\%)\end{array}$ & $\begin{array}{l}\text { Hospitalization } \\
\text { rate (\%) }\end{array}$ & $\begin{array}{l}\text { Outpatient } \\
\text { rate } \\
(\%)\end{array}$ & $\begin{array}{l}\text { Non- } \\
\text { admission } \\
\text { rate (\%) }\end{array}$ & $\begin{array}{l}\text { Hospitalization } \\
\text { reimbursement } \\
\text { ratio (\%) }\end{array}$ \\
\hline \multirow[t]{3}{*}{ Family size } & 1 & 14.1 & 15.6 & 19.8 & 6.3 & 41.1 \\
\hline & $2-3$ & 13.6 & 13.5 & 19.3 & 5.7 & 52.8 \\
\hline & $\begin{array}{l}\text { More } \\
\text { than } 3 \\
\text { people }\end{array}$ & 13.8 & 14.7 & 24.0 & 8.3 & 49.1 \\
\hline \multirow{2}{*}{$\begin{array}{l}\text { Hospitalization } \\
\text { members }\end{array}$} & Yes & 24.7 & / & 34.2 & 13.1 & 44.6 \\
\hline & No & 12.3 & / & 17.3 & 5.0 & / \\
\hline \multirow{2}{*}{$\begin{array}{l}\text { Having } \\
\text { disabled } \\
\text { members }\end{array}$} & Yes & 21.7 & 17.2 & 21.8 & 9.9 & 40.3 \\
\hline & No & 13.4 & 14.6 & 19.6 & 5.8 & 46.0 \\
\hline \multirow{4}{*}{$\begin{array}{l}\text { Combined with } \\
\text { other chronic } \\
\text { diseases }\end{array}$} & No & 12.0 & 13.3 & 17.7 & 5.3 & 45.3 \\
\hline & 1 & 14.0 & 15.3 & 20.8 & 6.0 & 46.8 \\
\hline & 2 & 16.6 & 14.6 & 20.0 & 7.4 & 49.1 \\
\hline & $\geqq 3$ & 13.8 & 23.5 & 24.5 & 9.8 & 48.5 \\
\hline \multirow{5}{*}{$\begin{array}{l}\text { Medical } \\
\text { insurance } \\
\text { schemes }\end{array}$} & MIUE & $8.6 \%$ & 20.4 & 20.0 & 3.3 & 69.8 \\
\hline & MIUR & 15.5 & 18.4 & 19.1 & 8.5 & 52.0 \\
\hline & NCMS & 14.3 & 13.7 & 20.5 & 6.6 & 39.7 \\
\hline & $\begin{array}{l}\text { Integrated } \\
\text { insurance }\end{array}$ & 14.7 & 16.3 & 23.3 & 4.7 & 54.2 \\
\hline & $\begin{array}{l}\text { Others } \\
\text { and not } \\
\text { having } \\
\text { insurance }\end{array}$ & 13.0 & 13.5 & 14.3 & 7.2 & 59.2 \\
\hline \multirow{5}{*}{$\begin{array}{l}\text { Economic } \\
\text { quintile }\end{array}$} & Lowest & 13.1 & 14.9 & 19.9 & 6.3 & 41.8 \\
\hline & 2 & 12.4 & 14.8 & 19.5 & 6.2 & 42.5 \\
\hline & 3 & 14.2 & 13.4 & 19.6 & 5.2 & 38.3 \\
\hline & 4 & 15.8 & 14.8 & 19.6 & 6.8 & 42.7 \\
\hline & Highest & 14.0 & 16.4 & 20.9 & 6.5 & 49.2 \\
\hline Overall & & 11.4 & 14.8 & 19.8 & 6.2 & 44.5 \\
\hline
\end{tabular}

Regarding health service utilization for the high-risk group of elderly CVD patients,the rate of monthly prevalence was $11.4 \%$ overall. A higher proportion of patients with CVD used inpatient services (14.8\%), and 
more than $19.8 \%$ of respondents reported the utilization of outpatient services over the past month. The above indicators demonstrate different trends for different populations with cardiovascular diseases as follows:

Cardiovascular patients with a high level of health service demand but low utilization of health services and low reimbursement rate. For example, families with cardiovascular disease patients and $>3$ other chronic diseases had a high demand for health services. Its prevalence rate and hospitalization rate were $13.8 \%$ and $23.5 \%$, respectively. However, the health service utilization (non-admission rate $9.8 \%$ ) and the reimbursement level (48.5\%) were lower than cardiovascular disease patients without other chronic diseases.

In terms of family economic level and type of medical insurance, cardiovascular patients with a high level of health service demand and high health utilization but low reimbursement. Household heads of cardiovascular diseases with NCMS had a higher prevalence (14.3\%) and outpatient rate (20.5\%), but the hospitalization reimbursement ratio (39.7\%) was lower by nearly $30 \%$ than MIUE (69.8\%). Patients who participated in MIUR of cardiovascular diseases demonstrated a similar pattern. It is worth noting that among the wealthiest households with cardiovascular diseases, the hospitalization rate and visit rate were $16.4 \%$ and $20.9 \%$, respectively, but the hospitalization reimbursement ratio was only $49.2 \%$, less than $50 \%$.

\section{$\mathrm{CHE}$, and IME in different households}

Table 4.CHE, and IME in different households 
Table 4

CHE, and IME in different households

\begin{tabular}{|c|c|c|c|c|}
\hline & & $\begin{array}{l}\text { Incidence of } \\
\mathrm{CHE}(\%)\end{array}$ & $\begin{array}{l}\text { Incidence of } \\
\text { IME (\%) }\end{array}$ & $\begin{array}{l}\text { OOP/CTP } \\
(\%)\end{array}$ \\
\hline \multirow[t]{3}{*}{ Family size } & 1 & 22.6 & 8.6 & 21.1 \\
\hline & $2-3$ & 15.6 & 6.2 & 13.7 \\
\hline & More than 3 people & 14.4 & 3.6 & 12.8 \\
\hline \multirow[t]{2}{*}{ Hospitalization members } & Yes & 29.3 & 8.7 & 28.4 \\
\hline & No & 18.6 & 7.5 & 15.6 \\
\hline \multirow[t]{2}{*}{ Having disability members } & Yes & 31.1 & 10.3 & 35.6 \\
\hline & No & 19.5 & 7.4 & 16.7 \\
\hline \multirow[t]{5}{*}{ Health satisfaction } & Very good & 17.1 & 4.1 & 17.0 \\
\hline & Good & 17.3 & 5.8 & 17.5 \\
\hline & Fair & 17.5 & 7.7 & 14.1 \\
\hline & Poor & 24.4 & 8.5 & 21.7 \\
\hline & Very poor & 30.5 & 10.0 & 25.3 \\
\hline \multirow{4}{*}{$\begin{array}{l}\text { Combine other chronic } \\
\text { diseases }\end{array}$} & No & 14.7 & 6.1 & 14.6 \\
\hline & 1 & 20.2 & 6.8 & 18.8 \\
\hline & 2 & 27.0 & 10.5 & 19.2 \\
\hline & $\geqq 3$ & 31.8 & 14.2 & 22.8 \\
\hline \multirow[t]{5}{*}{ Medical insurance } & MIUE & 13.3 & 3.1 & 13.0 \\
\hline & MIUR & 15.1 & 4.5 & 13.8 \\
\hline & NCMS & 21.6 & 9.0 & 19.7 \\
\hline & Integrated insurance & 20.5 & 5.1 & 6.1 \\
\hline & $\begin{array}{l}\text { Others and not having } \\
\text { insurance }\end{array}$ & 16.3 & 3.8 & 15.3 \\
\hline \multirow{5}{*}{$\begin{array}{l}\text { Household consumption per } \\
\text { capital quintile }\end{array}$} & Lowest & 19.3 & 8.3 & 17.9 \\
\hline & 2 & 22.5 & 10.1 & 22.1 \\
\hline & 3 & 20.4 & 7.8 & 18.4 \\
\hline & 4 & 19.5 & 5.9 & 16.2 \\
\hline & Highest & 17.5 & 5.5 & 13.6 \\
\hline Overall & / & 19.9 & 7.6 & 17.2 \\
\hline
\end{tabular}


We further measured the incidence of CHE and IME in elderly with CVD, and $19.9 \%$ of all interviewed CVD patients encountered $\mathrm{CHE}$, and the IME occurred in $7.6 \%$ of the overall population.

We also found that as the family size increased for CVD patients, the risk of households being trapped in CHE and IME was reduced.. For example, the incidence of $\mathrm{CHE}$ among the household with one people(8.1\%) was twice that of having no other diseases (14.7\%). Furthermore, families with inpatients and disability members of CVD increased the risk of CHE and had a greater financial burden.,and the incidence of CHE were $29.3 \%$ and $31.1 \%$, which is more than $10 \%$ higher than that of those without inpatients and disability members of $\operatorname{CVD}(18.6 \%$ and $19.5 \%)$

It is worth noting that income level is not the main reason for the high incidence of CHE in patients with CVD. Among them, sub-poor families with CVD had the highest incidence rate of CHE $(22.5 \%)$ and health expenditure burden(22.1\%),,respectively,higher than the richest households with CVD .As far as the type of insurance is concerned, among the three basic medical insurances, cardiovascular families with NCMS had the greatest economic burden of disease, and the risk of CHE was also the highest (21.6\%), nearly $8.3 \%$ higher than that of NIUE (13.3\%).

\section{The treatment-effect model for patients with CVD}

Table 5. Results of treatment-effect model for patients with CVD 
Table 5

Results of treatment-effect model for patients with CVD

\begin{tabular}{|c|c|c|c|c|c|c|}
\hline & Coef. & Std. Err. & z & $P>|z|$ & 95\% C.I. & \\
\hline \multicolumn{7}{|l|}{ CHE } \\
\hline Marital status of household head & 0.0129 & 0.0233 & 0.53 & 0.599 & -0.0335 & 0.0581 \\
\hline Region & -0.0209 & 0.0116 & -1.79 & 0.073 & -0.0438 & 0.0019 \\
\hline Gender of household head & 0.0081 & 0.0174 & -0.47 & 0.640 & -0.0424 & $0 . .0261$ \\
\hline Education level of household head & 0.0016 & 0.0151 & 0.11 & 0.915 & -0.0281 & 0.0313 \\
\hline Household consumption per capital quintile & -0.0069 & 0.0061 & -1.12 & 0.262 & -0.0190 & 0.0052 \\
\hline Family size & -0.0499 & 0.0138 & -3.61 & 0.000 & -0.0770 & -0.0227 \\
\hline Urban and rural & -0.0379 & 0.0203 & -1.86 & 0.063 & -0.0779 & 0.0019 \\
\hline Health satisfaction & 0.0246 & 0.0093 & 2.64 & 0.008 & 0.0063 & 0.0429 \\
\hline Having disabled members & 0.0961 & 0.0473 & 2.03 & 0.042 & 0.0033 & 0.1889 \\
\hline Having members over 65 years old & 0.0129 & 0.0171 & 0.76 & 0.450 & -0.0206 & 0.0465 \\
\hline Combined with other chronic diseases & 0.0468 & 0.0088 & 5.32 & 0.000 & 0.0296 & 0.0641 \\
\hline Having hospitalized members & 0.1001 & 0.0252 & 3.97 & 0.000 & 0.0506 & 0.1495 \\
\hline Having insurance & 0.2895 & 0.1454 & 1.99 & 0.047 & 0.0044 & 0.5745 \\
\hline \multicolumn{7}{|l|}{ Having insurance } \\
\hline Community participation rate & 0.0571 & 0.0056 & 10.08 & 0.000 & 0.0460 & 0.0682 \\
\hline
\end{tabular}

Community participation rate was added as an effective instrumental variable to the treatment-effect model. The results were as follows: family size, health satisfaction, combination with other chronic diseases, having hospitalization members, having disabled members, and participating in insurance were all found to be significantly associated with the odds of encountering CHE with CVD $(P<0.05)$.

Social demographic perspective. The incidence of CHE and family size with CVD have developed in reversethat is,as the cardiovascular family grows in size, the risk of $\mathrm{CHE}$ is reduced by 4.99 percentage points.

Health needs and utilization perspective Combination with other chronic diseases, health satisfaction,having hospitalization members, and having disabled members had a positive correlation with the risk of CHE in cardiovascular patients, and with an increase of combining other chronic diseases or hospitalization members increased,the risk of a family's CHE increased by 4.68 percentage points and 10.01 percentage points, respectively.

Medical insurance perspective It is worth noting that cardiovascular patients participating in medical insurance increased, the risk of $\mathrm{CHE}$ and increased the risk of being trapped in $\mathrm{CHE}$ by 28.9 percentage points. 


\section{Medical insurance level}

As shown in the above figure, among patients with cardiovascular disease, rural population accounts for $75.1 \%$ of the sample size, and the CHE of NCMS was the riskiest, at 21.6\%. In addition, the treatment-effect model shows that the probability of CHE participating in health insurance families with cardiovascular disease has increased by 29.8 percentage points. Therefore, to identify the NCMS of key bottlenecks, we conducted a specific influencing factor analysis and found that families with cardiovascular disease combined with $>3$ other chronic diseases (38.88\%) were the primary cause of high CHE in NCMS. Next, in turn, being more than 75 years old (33.33\%), having disabled members (33.33\%), having hospitalization members (32.41\%), and combining two chronic diseases (30.74\%) were the top five factors influencing high $\mathrm{CHE}$ of families with cardiovascular disease in NCMS.The results are presented in Fig. 1.

\section{Discussion}

The proportion of households associated with CHE and IME in elderly patients with CVD were $19.9 \%$ and $7.6 \%$, respectively. These rates were higher than those of developed countries,but were lower than those of lowincome countries. ${ }^{29,30}$ The incidences of CHE participating in medical insurance were $3.6 \%$ higher than those of uninsured households (16.3\%). In addition, families with cardiovascular disease have a much higher risk of IME than families without cardiovascular disease $(7.0 \%)$ and the overall population $(7.2 \%)$.It can be seen that cardiovascular disease patients' risk tolerance for health care payments is actually lower than the average in China. At the same time, our study also found that cardiovascular families with chronic patients, inpatients, and disabled members, are at a higher risk of falling into poverty because of the cost of health care, and they are becoming a stubborn group with a high burden of CVD disease under the medical insurance system.

As a kind of vulnerable group, patients with cardiovascular disease are mainly characterized as a high-risk group integrating physiological, social, and health factors. We need to identify risk factors for patients with CVD and identify vulnerable groups and then better play the economic protection role of the medical insurance system. As mentioned earlier, despite these governmental efforts, many disadvantaged groups are not considered target populations for benefit enhancement. Through comprehensive analysis, we found that the disadvantaged elderly population with mental health has the following characteristics:

\section{Older groups with physical vulnerability are more prone to $\mathrm{CHE}$.}

In the first place, age growth, loss of healthy capital, and decline in physiology are inevitable for the elderly. However, elderly people are at a disadvantage in accessing resources and fail to enjoy social welfare policies fairly. ${ }^{31,32}$ For example, the incidence of CHE in elderly people over 75 years old in the NCMS was $33.33 \%$, second only to the merger of three chronic diseases (33.88\%). The WHO reported that $23 \%$ of the world's disease burden is on older people, and chronic non-communicable diseases have a major impact on this burden. ${ }^{33}$ Furthermore, the morbidity and concurrency of elderly patients with CVD may eventually lead to premature death and disability, while long-term health care costs, drug costs, and rehabilitation costs greatly increase the risk of $\mathrm{CHE}^{34}$ Our results show that the hospitalization rate (23.5\%), rate of visits $(24.5 \%)$, and incidence of CHE (31.8\%) of patients with more than three chronic diseases are far higher than those without chronic diseases $(13.3 \%, 17.7 \%, 14.7 \%$, respectively), and the treatment-effect model shows that the combination with other 
chronic diseases increases the risk of 4.68 percentage points of CHE. Past evidence has demonstrated that the likelihood of using health care (e.g, hospitalization) increases in the presence of chronic or multiple conditions. ${ }^{35}$ It can be seen that with the increase of the number of chronic diseases, the addition of other chronic diseases will prolong the hospitalization time on the basis of the original single disease, which will cause CVD patients to superimpose the cost of other diseases when they bear the economic pressure from their cardiovascular disease burden. Studies have found that one-third of adults have multiple chronic diseases, equivalent to $3 / 4$ of the elderly in developed countries. ${ }^{36}$ Therefore, suffering from a variety of chronic diseases has become a major health problem for the elderly in the future, greatly increasing the risk of CHE.

\section{The medical insurance system only guarantees the basic health utilization threshold for elderly patients with CVD and lacks policy inclination for high-utilization populations.}

The existing medical insurance system reduces the threshold of health service utilization for vulnerable groups. such as those with cardiovascular diseases, but only achieves the first goal of medical insurance-that is, to ensure that all people have access to high-quality care. Our results show that the incidence of CHE for highdemand people with inpatients and disabled patients is much higher than that of the normal population. In our paper, families with disabled patients had higher prevalence (21.7\%) and outpatient rates (21.8\%) than those without disabilities ( $13.4 \%$ and $19.6 \%$, respectively). However, the hospitalization reimbursement ratio was only $40.6 \%$, far below the overall level (44.5\%), and OOP accounted for $35.6 \%$ of total household health expenses, which is much higher than that of OECD countries. ${ }^{37}$ A study in South Korea showed that families with disabilities face higher CHE than those without people with disabilities, and annual living expenses for OOP medical expenses are roughly 1.2 to 1.4 times greater. ${ }^{38}$ This may be due to physical or mental disability in disabled patients leading to job loss or reduced earnings, while higher medical care needs due to disability increase the burden of high medical costs. ${ }^{39}$ Even relatively small expenditures are catastrophic for poor families, and excessive out-of-pocket health care spending can lead to poverty. ${ }^{40}$

\section{The medical insurance system has poorly accurate identification of vulnerable characteristics, which in turn affects the economic protection ability of the medical insurance system for patients with cardiovascular diseases.}

China's medical insurance policy aims to solve the problem of "people falling into poverty due to illnesses" and to ensure that most people are not reduced to poverty because of health-related issues. However, our results indicate that the risk of CHE for CVD patients participating in medical insurance schemes has increased by $28.9 \%$, which had the highest incidence of CHE for NCMS. It can be seen that the medical insurance system has the disadvantages of insufficient protection of policies in reducing the economic burden of residents' medical care and maintaining residents' health rights and health. China's health sector reform has achieved unprecedented progress, but protecting vulnerable groups from health care-related impoverishment remains a challenge. Specifically, we need to reconsider benefit packages and redesign social health care insurance programs in order to further protect the elderly population with cardiovascular disease.

Inequality between types of health insurance systems: binary urban and rural structure divided by place of residence. The household registration system in China directly affects the ability to obtain various medical benefits. ${ }^{41}$ In our paper, the hospitalized reimbursement ratio of MIUE with cardiovascular disease patients was 
$69.8 \%$, while that of the NCMS was only $39.7 \%$, accounting for only half of the MIUE. Urban residents are expected to have a greater awareness about their health and better access to health insurance (especially private health insurance) and hence are more likely to obtain health insurance. The health needs of people in rural areas are not able to be converted into effective medical needs in time due to lower income levels, high medical prices, and inadequate medical care, thus bearing the risk of greater CHE. A Chinese study shows that NCMS cannot prevent CHE from happening in poor families but only reduces the incidence of CHE in wealthy families. ${ }^{42}$ This differentiated design of health care benefits can sometimes lead to social inequalities, often with the same disease, at different costs, and patients with higher socioeconomic status usually enjoy better health insurance and higher service utilization. In rural areas, this should further increase the reimbursement ratio of outpatient and inpatient expenditures to the elderly with cardiovascular diseases who receive treatment at every kind of hospital. ${ }^{43}$

Inequality of different income groups under the same medical insurance system. Our research indicated that the incidence of CHE in sub-poor households with CVD (22.5\%) was higher than 5\% of households with the highest income. Its OOP accounts for $22.1 \%$ of CTP, and the economic burden of disease was higher than that of highincome families by nearly $10 \%$. A similar phenomenon occurred in India. According to the data, India's medical expenditure accounts for only $0.9 \%$ of the GDP, which is lower than the $2.8 \%$ of the GDP of less developed countries. However, with only government spending, among the five economic subgroups, the poorest households with less income receive only $10 \%$ of medical care, while $20 \%$ of the wealthiest households receive up to $33 \%$ of social subsidies, three times as much as the poorest households. ${ }^{44}$ The heavy burden of disease can lead to a difficult family life in low-income groups, which thus fall into the evil cycle of "poor illness due to illness and illness due to poverty." Therefore, the internal system design of medical insurance should strengthen the economic support and protection for poor families and achieve certain policy inclinations.

\section{The inconsistencies between multiple health care systems lead to blind spots in the economic risk protection of individuals and families.}

China has established multiple medical security systems, including basic medical insurance, major illness insurance, commercial medical insurance, social medical assistance, and charity assistance. However, the complexity of cardiovascular disease and the difference in the income of the population mean that various systems have not woven a standard, unified safety net to prevent impoverishment by medical expense, which is mainly reflected in the following two points.

Firstly, the particularity of cardiovascular disease can lead to the loss of labor, the indirect cost of nursing expenses, and transportation expenses, and long-term drug maintenance will also increase the economic burden of patients. These neglected indirect costs and drug costs have become blind spots in the economic protection of basic health care systems. In our study, elderly cardiovascular patients still have to pay more than half (55.5\%) of their medical expenses after reimbursement by basic medical insurance schemes. Moreover, there is no effective mechanism to connect basic insurance schemes, major disease schemes, and medical assistance insurance systems, resulting in this group of patients falling into poverty after paying for the high medical expense.

Secondly, our result also shows that sub-poor households have the highest incidence of CHE at $22.5 \%$, and the OOP accounts for $22.1 \%$ of CTP, much higher than the poorest households. The medical security system has 
implemented certain health expense reduction policies for these "extremely poor families" without economic sources or micro-income, including lowering the deductible line, increasing the proportion of reimbursement, and improving or eliminating top-up measures. The high-risk marginalized population with an economic income slightly higher than that of the poorest households, which is prone to $\mathrm{CHE}$, has not reached the standard of assistance for supplementary medical assistance and has failed to be covered by a multilevel medical security system.

It can be seen that exploring the integration of multilevel medical insurance systems, promoting the complementary functions and overlapping effects of multilevel medical insurance systems, and jointly solving the poverty problems caused by cardiovascular patients have become the target task of the current prevention and treatment process of chronic diseases.

\section{Conclusions}

The findings revealed that the incidence of $\mathrm{CHE}$ and IME were relatively high among elderly households with CVD patients. The elderly who had poor health satisfaction, combination with other chronic diseases, inpatients, and disabled people were the high-risk groups of CVD. Medical insurance programs have not reduced the risk of CHE or relieved the financial burden of CVD patients in China, especially the elderly who participate in the NCMS. Therefore, there is an urgent need for Chinese policymakers to improve the accuracy of medical health insurance schemes to target the vulnerable characteristics of elderly cardiovascular patients. While improving the accessibility of health services for cardiovascular patients, the next step should be to focus on achieving another function of the medial health insurance system, which is to maximize the economic protection for the vulnerable en-rollers and reducing their risk of being trapped in the poverty, rather than increasing the risk. It is worth noting that our research has its limitations. First, the data were self-reported surveys that may be affected by measurement errors. Second, the study used cross-sectional samples rather than panel data, making it difficult to test the long-term effects of health insurance and other control variables on CHE in cardiovascular patients.

\section{List Of Abbreviations}

\section{Cardiovascular disease: CVD}

Catastrophic Health Expenditure区CHE;

Impoverishment by Medical Expenses: IME;

Urban employees' Insurance Medical: MIUE;

Urban resident Insurance Medical: MIUR ;

New rural Cooperative Medical System: NCMS;

Poverty Line: pl

Household subsistence expenditure: SE; 
A household's capacity to pay: CTP

Out-of-pocket health expenditure: OOP

Household consumption expenditure: EXP

Instrumental Variable: IV

\section{Declarations}

\section{Ethics approval and consent to participate:}

Not applicable

\section{Consent for publication:}

Not applicable

\section{Availability of data and materials:}

Dataset available from the CHARLS repository, http://charls.pku.edu.cn.

\section{Competing interests:}

The authors declare that they have no competing interests.

\section{Funding:}

This work was supported by the National Natural Science Foundation (71874045,

71403073,71333003,71804036) 『China Postdoctoral Science Foundation (2016M590296)ロand Heilongjiang Postdoctoral Foundation (LBH-Z14166). The funder had no role in the design of the study, collection, analysis, and interpretation of data, or manuscript preparation.

\section{Authors' contributions:}

MYM conducted literature search, planned the study, carried out data collection, performed data analysis and interpretation and drafted the manuscript.YL, QHW and TS conducted frame design, easibility analysis and helped conceptualize the project .NSW,MLJ and LHS reviewed literature search and data analysis.,HL,HG and XLF revised the manuscript and gave critical feedback.WXT, QX,YHH and BGS conducted quality control and review of manuscripts.All authors have read and approved the manuscript.

\section{Acknowledgement:}


Each author contributed to the concept, design, research, data analysis, drafting of the article,and we acknowledge the outstanding contributions of Nianshi Wang, Mingli Jiao, who contributed equally to the first author of this article.I have obtained written permission from all persons named in the Acknowledgement.

\section{References}

1. Li Y, Wang D D , Ley S H , et al. Potential Impact of Time Trend of Life-Style Factors on Cardiovascular Disease Burden in China. J Am Coll Cardiol,2016, 68(8):818-833.

2. Tuppin $P$, Rivière, Sébastien, Rigault $A$, et al. Prevalence and economic burden of cardiovascular diseases in France in 2013 according to the national health insurance scheme database. Arch Cardiovasc Dis, 2016:S187521361630047X.

3. Hsu W Y . A decision-making mechanism for assessing risk factor significance in cardiovascular diseases. Decis Support Syst,2018, 115:64-77.

4. GBD 2015 Eastern Mediterranean Region Cardiovascular Disease Collaborators. Burden of cardiovascular diseases in the Eastern Mediterranean Region, 1990-2015: findings from the Global Burden of Disease 2015 study. Int J Public Health, 2018, 63(Suppl 1):1-13.

5. China Cardiovascular Disease Report 2018. Edited by the National Cardiovascular Center. Beijing: China Encyclopedia Publishing House, 2019. 1.

6. Zhou M, Wang H, Zhu J, et al. Cause-specifific mortality for 240 causes in China during 1990-2013: a systematic subnational analysis for the Global Burden of Disease Study 2013. Lancet. 2016; 387:251-72. 7. Al-Mallah M H , Farah I, Al-Madani W , et al. The Impact of Nurse-Led Clinics on the Mortality and Morbidity of Patients with Cardiovascular Diseases: A Systematic Review and Meta-analysis. J Cardiovasc Nurs, 2016, 31(1):89.

8. National Academies of Sciences, Engineering,and Medicine. Global Health and the Future Role of the United States: A Report of the National Academies of Sciences, Engineering, and Medicin by the Committee on Global Health and the Future of the United States, Board on Global Health, Health and Medicine Division. Washington, DC:The National Academies Press, 2017.

9. Engelgau MM, Saharty S, Kudesia P, et al. Capitalizing on the demographic transition: Tackling noncommunicable diseases in South Asia. World Bank: Washington, DC; 2011.

10. Murray CJ, Vos T, Lozano R, et al. Disability-adjusted life years $₫ D A L Y s \rrbracket$ for 291 diseases and injuries in 21 regions,1990-2010: a systematic analysis for the Global Burden of Disease Study 2010. Lancet. 2012,380 ख9859凶:2197-2223.

11. National Center for CVDs of China. Report on CVDs in China (2016). Beijing, China:Encyclopedia of China Publishing House, 2017.

12. Yusuf S, Reddy S, Anand S. Global Burden of Cardiovascular Diseases Part II: Variations in Cardiovascular Disease by Specific Ethnic Groups and Geographic Regions and Prevention Strategies. Circulation, 2001, 104(23):2855-2864.

13. Australian Institute of Health and Welfare (AlHW). Australia's Health 2014; Australia's Health Series No.

14;Cat. No. AUS 178; AlHW: Canberra, Australia, 2014. Published online on February 1 2017. https://www. aihw. gov. au/reports/australias-health/australias-health-2014/contents/table-of-contents .

14. World Bank: Toward a Healthy and Harmonious Life in China: Stemming the Rising Tide of NonCommunicable Diseases. 2011. Published online on July 26 2011. https://www. worldbank. org/en/news/feature/2011/07/26/toward-health-harmonious-life-china-stemming-rising-tide-of-non- 
communicable-diseases.

15. Li Y , Wu QH , Li CJ, et al. Catastrophic Health Expenditure and Rural Household Impoverishment in China: What Role Does the New Cooperative Health Insurance Scheme Play? Plos one, 2014, 9(4):e93253- e93253. 16. Fanourgiakis J, Kanoupakis E. Catastrophic healthcare expenditure during economic recession in the field of cardiovascular disease. Expert Rev Pharm Out, 2014,14(1):5-8.

17. Liu X, Sun $X$, Zhao $Y$, et al. Financial protection of rural health insurance for patients with hypertension and diabetes: repeated cross-sectional surveys in rural China. BMC Health Serv Res, 2016, 16(1):481.

18. Li C, Jian W. Economic burden of cardiovascular disease in middle-aged and elderly people-An empirical analysis based on China's health and pension tracking survey. Chinese Journal of Health Policy Research, 2017, 10(5): 75-80.

19. European Commission. Published online on March 26,2014. https://ec. europa.

eu/eurostat/en/web/products-statistical-working-papers.

20. World Health Organization. Health Financing Strategy for the Asia Pacific Region (2010-2015) .

Switzerland:World Health Organization, 2009.

21. Xu K. Distribution of health payments and catastrophic expenditures methodology. Geneva: Department of Health System Financing, World Health Organization,2005.

22. Wooldridge $\mathrm{J} \mathrm{M}$. Further results on instrumental variables estimation of average treatment effects in the correlated random coefficient model. Econ Lett, 2003, 79(2):185-191.

23. Jelena A, Milena P, Bernd R, Wim G. Catastrophic Health Care Expenditure among Older People with Chronic Diseases in 15 European Countries. Plos One. 2016;11(7):e0157765.

24. Lewbel A . Endogenous selection or treatment model estimation. J Econometrics, 2007, 141(2):777-806. 25. Wang XW. A Study on the Impact of Health on the Labor Supply Behavior of the Mid-aged and Elderly of China. Anhui University of Finance and Economics,2016.

26. Hu HW, Zhang L, Li JY, Du YX, Wang JR. Does Urban Residents Basic Medical Insurance Worsen the Medical Burden to the Elderly?-System Evaluation with Household Medical Burden. Chinese Scientific Research on Aging,2015;(4):51-61.

27. Gu NY, Gai Y, Hay JW. The effect of patient satisfaction with pharmacist consultation on medication adherence: An instrumental variable approach. Pharm Pract,2008;6(4).

28. Hall AR. , Rudebusch GD, Wilcox DW. Judging Instrument Relevance in Instrumental Variables Estimation. Int Econ Rev,1996;37(2):283-298.

29. Jelena Arsenijevic . Catastrophic Health Care Expenditure among Older People with Chronic Diseases in 15 European Countries. PLosOne. 2016; 11(7): e0157765.

30. Tolla M T , Norheim O F , Verguet, Stéphane, et al. Out-of-pocket expenditures for prevention and treatment of CVD in general and specialised cardiac hospitals in Addis Ababa, Ethiopia: a cross-sectional cohort study.

BMJ Glob Health, 2017, 2(2):e000280.

31. Sónia Ribeiro, Cláudia Furtado, João Pereira. Association between cardiovascular disease and

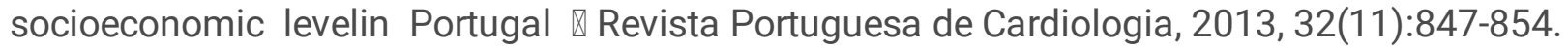

32. Ngalesoni F N , Ruhago G M , Mori A T , et al. Equity impact analysis of medical approaches to cardiovascular diseases prevention in Tanzania. Soc Sci Med, 2016:S0277953616304695.

33. WHO. Health in 2015: from MDGs to SDGs. Geneva: World Health Organization, 2015.

34. Dittrich L , Stara D. The Impact of Aging Population on the Rise of the Health Care Cost in the Czech Republic. Int Adva Econo Res, 2013, 19(1):11-17. 
35. Hopman $P$, Heins $M J$, Rijken $M$, et al. Health care utilization of patients with multiple chronic diseases in The Netherlands: Differences and underlying factors. Eur J Intern Med, 2015, 26(3):190-196.

36. Cother H,Emma S. The global burden of multiple chronic conditions: A narrative review. Prev Med Rep,2018,12(284-293).

37. Organization for Economic Cooperation and Development. Health at a glance 2013: OECD indicators. Published online on May 262015 . http://dx. doi. org/10. 1787/health_glance-2013-en.

38. Lee J E , Shin H I , Do Y K, et al. Catastrophic Health Expenditures for Households with Disabled Members: Evidence from the Korean Health Panel. J Korean Med Sci, 2016, 31(3).

39. Zuvekas S H , Selden T M . Mental Health and Family Out-of-Pocket Expenditure Burdens. Med Care Res Rev, 2010, 67(2):194-212.

40. Gotsadze G , Zoidze A, Rukhadze N. Household catastrophic health expenditure: evidence from Georgia and its policy implications. BMC Health Serv Res, 2009, 9(1):69-0.

41. Li C, Young B R, Jian W. Association of socioeconomic status with financial burden of disease among elderly patients with cardiovascular disease: evidence from the China Health and Retirement Longitudinal Survey. Bmj Open,2018, 8(3):e018703.

42. Guo N , Iversen T, Lu M , et al. Does the new cooperative medical scheme reduce inequality in catastrophic health expenditure in rural China? BMC Health Serv Res, 2016, 16(1):653.

43. Wang Z, Li X, Chen M . Catastrophic health expenditures and its inequality in elderly households with chronic disease patients in China. Int J Equity Health, 2015, 14(1):8.

44. Meng Q, Xu L, Zhang Y, et al. Trends in access to health services and financial protection in China between 2003 and 2011: a crosses ctional study. Lancet, 2012; 379: 805-14.

\section{Figures}




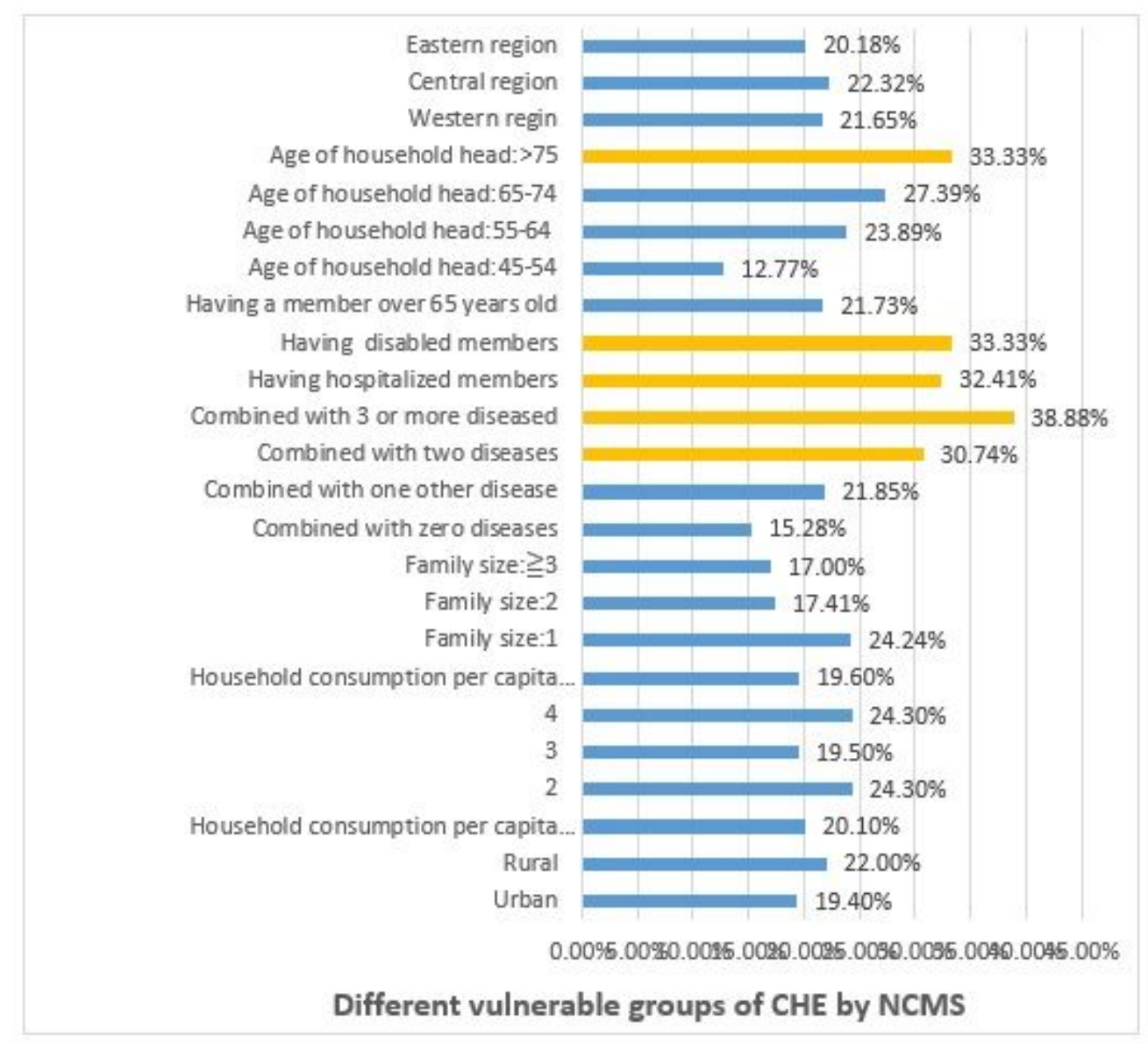

\section{Figure 1}

Different vulnerable groups of CHE by NCMS 